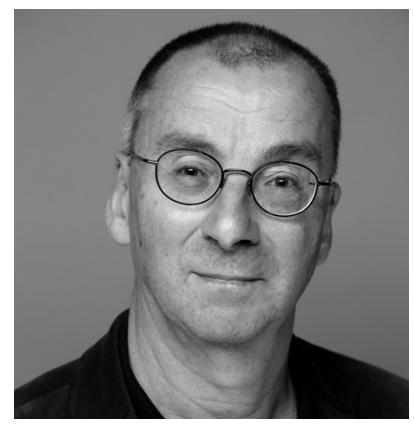

\section{Zwischen Gurkenrepublik und Möglichkeitsräumen}

Die wahren - und gelegentlich die erfundenen - Geschichten rund um die Europäische Union sind Legion. Die Verordnung Nr. 1677/88/EWG zur Festsetzung von Qualitätsnormen für Gurken (»Gurkenkrümmungsverordnung «), die es zwanzig Jahre lang wirklich gab, dient Kabarettisten und Stammtischen immer noch als Beleg für die »Brüsseler Bürokratie«. Doch wie jedes staatliche Handeln steht auch die Europäische Union im Spannungsfeld zwischen Regelungsnotwendigkeit und Freiheit. Und nicht die »Bürokratie« gefährdet das europäische Projekt, wie Joachim Rock in seinem Einleitungsbeitrag in diesem Heft knapp und einleuchtend darlegt, sondern der Unmut der Politik, ihr Handeln im Hinblick auf die Integration Europas nachvollziehbar darzustellen. Als ein Beispiel nennt der Autor den neuen Koalitionsvertrag zwischen CDU, CSU und SPD, der von Kommunikationsexperten der Universität Hohenheim auf seine Verständlichkeit hin untersucht wurde. Auf der Grundlage des »Hohenheimer Verständnisindexes", der von 0 (völlig unverständlich) bis 20 (sehr verständlich) reicht, wurde das Europakapitel des Koalitionsvertrages mit 1,8 als das am schlechtesten verständliche Kapitel bewertet. Ausgerechnet, so Joachim Rock, die europäische Politik werde in »Fachchinesisch" transportiert. Die auch durch solches Verhalten der Politik provozierte Debatte über Renationalisierung stelle keine Feuilleton-Diskussion dar. Für die Sozialwirtschaft sei sie vielmehr von grundlegender Bedeutung: In dieser Auseinandersetzungen werden die "Möglichkeitsräume sozialen Wirtschaftens" abgesteckt. Drei Aspekte stünden dabei im Vordergrund: die Gretchenfrage nach der sozialen Dimension, die Frage der Finanzierungsbedingungen Sozialer Arbeit und die europarechtliche Regulierung von Wettbewerbsverhältnissen. Sein Resümee: »Nationale Reservate gibt es nicht mehr.«

Seit Kurzem stehen die Ausgaben und Artikel der Zeitschrift SOZIALwirtschaft für Abonnenten der Druckausgabe auch im Nomos-Zeitschriften-Portal (www. nomos-zeitschriften.de) online zur Verfügung. Über die Zugangsmöglichkeiten für Privatbezieher und Institutionen informiert Sie gerne Aloisia Hohmann von der Vertriebsabteilung des Nomos-Verlages (hohmann@nomos.de).

Gerhard Pfannendörfer, Chefredaktion pfannendoerfer@nomos.de 